\title{
Origin of Exo/Endo Selectivity in the Intramolecular Diels-Alder Reaction
}

\author{
Shihai Yan, ${ }^{\dagger+}$ Do Hyun Ryu, ${ }^{\dagger}$ and Jin Yong Lee ${ }^{\dagger, *}$ \\ ${ }^{\dagger}$ Department of Chemistry, Sungkyunkwan University, Suwon 440-746, Korea. *E-mail: jinylee@skku.edu \\ ${ }^{\ddagger}$ Qingdao Institute of Bioenergy and Bioprocess Technology, Chinese Academy of Sciences, Qingdao, 266101, China \\ Received June 7, 2010, Accepted July 16, 2010
}

\begin{abstract}
The stereoselectivity of the intramolecular Diels-Alder reactions of $\mathbf{1}$ and its derivatives were investigated by ab initio calculations. The stereoselectivity mainly originates from the steric repulsion and the orbital interactions. The additional $s$-cis and s-trans conformations by introducing the carbonyl group at the neighbor of diene or dienophile may change the stereoselectivity, hence this kind of substitution can be utilized for stereoselectivive asymmetric synthesis.
\end{abstract}

Key Words: Intramolecular Diels-Alder reaction, DFT, Selectivity, Orbital interaction, Steric repulsion

\section{Introduction}

The Diels-Alder (DA) reaction ${ }^{1}$ is one of the most efficient and widely used approaches to carbon-carbon bond formation. Its mechanism has been a subject of importance, and sometimes gives controversies. For asymmetrically substituted dienes and dienophiles, DA reaction results in product selectivity due to the asymmetric transition state. It is well established that most DA cycloaddition reactions proceed through the concerted pathways. In this connection, the product selectivity of various DA reactions have been investigated by both the experimental and theoretical studies. ${ }^{2}$ Once we understand the origin of the product selectivity, we could design efficient reactants that could generate what we wanted through the enantioselective or diastereoselective DA reactions. Basically, the relative energy of the transition states (TSs) is responsible for the product selectivity because the reactants are the same.

Recently, a natural product, Tubelactomicin A, was synthesized stereoselectively by a Intramolecular Diels-Alder (IMDA) reaction. ${ }^{3}$ However, origin of the stereoselectivity was not explained. Thus, it should be very interesting to understand the
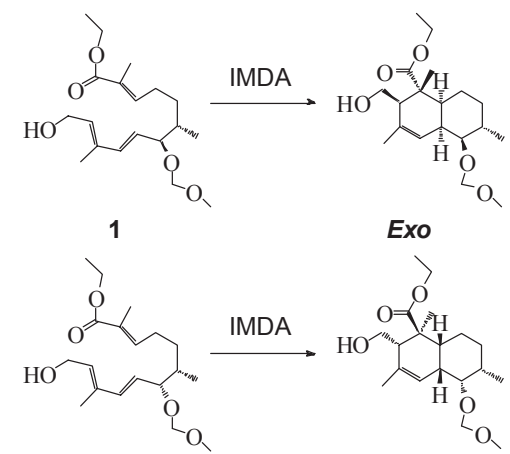

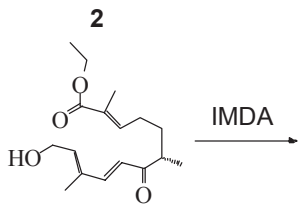

3

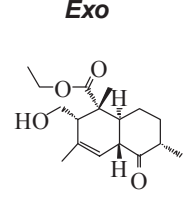

Endo
Figure 1. Exo/Endo-selective IMDA reactions of 1, 2, and $\mathbf{3}$. origin of the stereoselectivity. In this letter, we investigated origin of the stereoselectivity of the IMDA reactions of $(2 E, 6 S$, $7 S, 8 E, 10 E$ )-ethyl-12-hydroxy-7-methoxymetho-xy)-2,6,10trimethyldodeca-2,8,10-trienoate (1) and its derivatives, $\mathbf{2}$ and 3 (Figure 1). 2 has a different chirality from 1 at $\mathrm{C} 7$ with $R$ configuration, and $\mathbf{3}$ has a different substituent from $\mathbf{1}$ at $\mathrm{C} 7$ with a ketone instead of a methoxymethoxy group.

\section{Calculation Methods}

The designed exo and endo products of 1, 2, and 3 were shown in Figure 2. All the $24 \mathrm{TS}$ structures were confirmed to be the correct TSs from the one negative frequency and the normal modes are consistent with the IMDA reactions coordinates. The density functional theory (DFT) calculations have been successful in explaining the product selectivity for the intramolecular DA reactions. ${ }^{4}$ In particular, the B3LYP exchange functional ${ }^{5}$ with $6-31 \mathrm{G}^{*}$ basis set has been very effective in predicting the structures and relative energies of the TSs for various intramolecular DA reactions, hence giving the exo/endo ratio consistent with experimental results. In recent studies, the energies obtained at the DFT calculations were failed to explain the experimental observation in several DA reactions because the DFT inherantly is lack of dispersive interactions. ${ }^{6}$ Thus, we carried out MP2/6-31+G(d) calculations at the B3LYP/6-31G* geometries as suggested in the earlier study. ${ }^{6}$ All the calculations were performed using a suite of Gaussian 03 programs.

\section{Results and Discussion}

The TSs of the IMDA reactions of $\mathbf{1}, \mathbf{2}$, and $\mathbf{3}$ were obtained at the B3LYP/6-31G* and the structures were shown in Figure 3. It has been indicated that the IMDA reactions proceeded predominantly through a boat-like TS. ${ }^{4 c, 8}$ Here, for $\mathbf{1}$ and $\mathbf{2}$, both the boat-like and the chair-like TSs have been explored for the exo and the endo cyclization. The TS structures and the relative energies were given in Figure 4, and only the lowest energy structures for the exo and endo cyclization were shown in Figure 3 in all the IMDA reactions investigated. For $\mathbf{1}$ and $\mathbf{2}$, there is a striking difference between the exo and the endo TS 

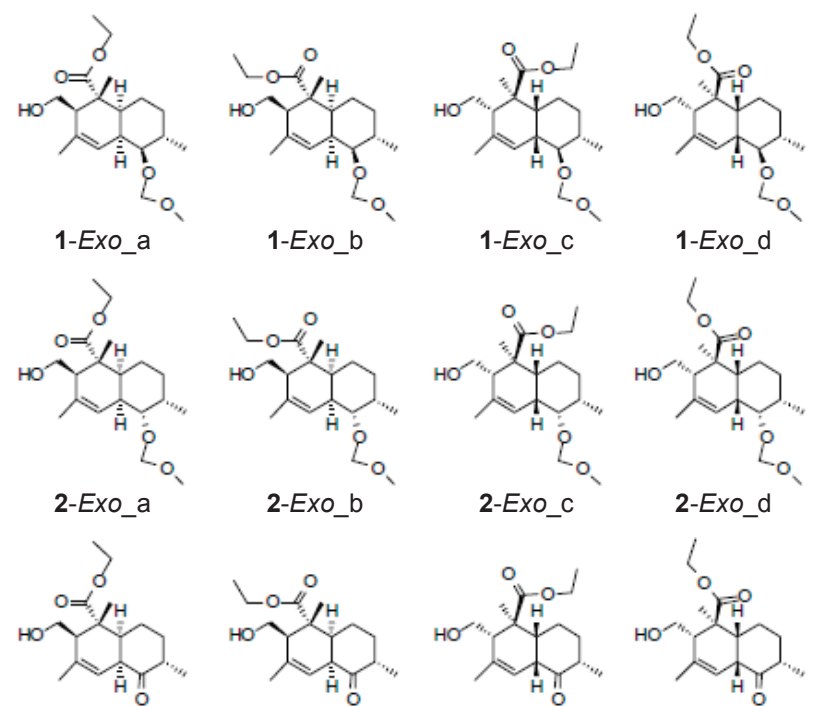

3-Exo_b

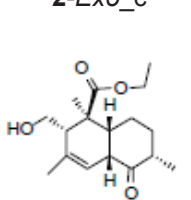

3-Exo_c

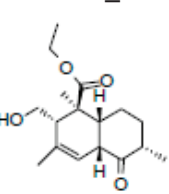

3-Exo_d
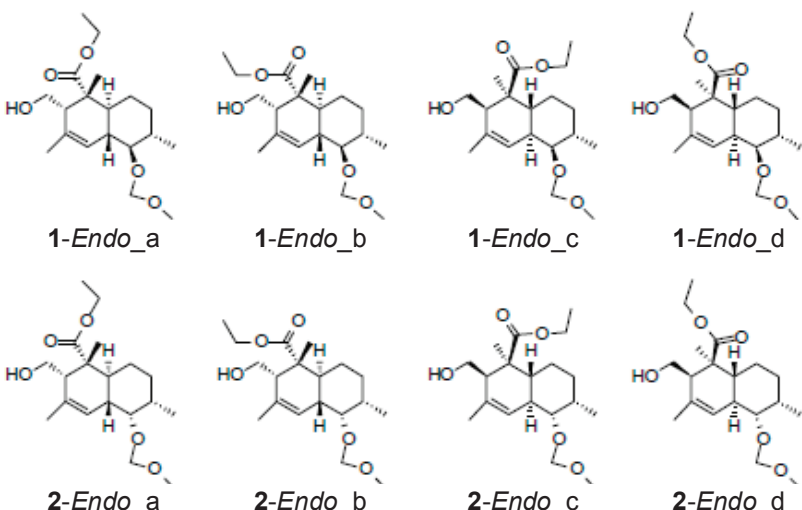

Figure 2. The designed exo and endo products of 1, 2, and $\mathbf{3}$.

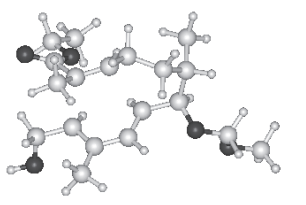

1 Exo boat-like (0.0)

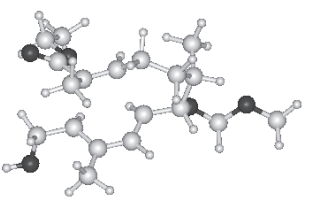

2 Exo boat-like (0.0)

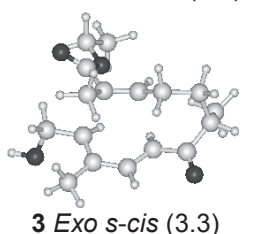

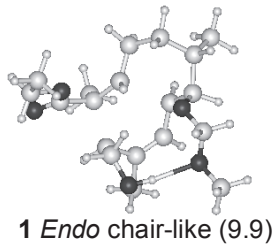

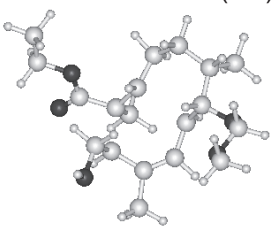

2 Endo chair-like (9.9)

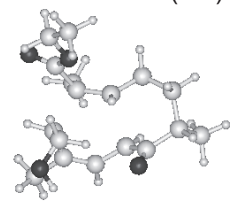

3 Endo s-cis (0.0)

Figure 3. B3LYP/6-31G* optimized transition state structures of 1, 2, and 3. Relative energies represented in the parenthesis are in $\mathrm{kcal} / \mathrm{mol}$. Oxygens are shown in black, Carbon and hydrogen atoms are in grey.

structures. The $\mathrm{C}_{1}-\mathrm{C}_{6}$ bond lengths in the exo TS are 2.202 and $2.164 \AA$ for 1 and 2, respectively, while those are 1.953 and $1.953 \AA$ in the endo TS. In addition, the dihedral angles of $\mathrm{C}_{2} \mathrm{C}_{3} \mathrm{C}_{4} \mathrm{C}_{5}$ in the exo TS are $56.2^{\circ}$ and $55.6^{\circ}$ for $\mathbf{1}$ and $\mathbf{2}$, respectively, while those are $-7.5^{\circ}$ and $7.0^{\circ}$ in the endo TS. On the other hand, the exo and endo TS structures are quite similar for 3. The DFT caculations resulted that the exo TSs for $\mathbf{1}$ and 2 are lower than the endo TSs by 11.1 and $9.9 \mathrm{kcal} / \mathrm{mol}$, respectively, which is consistent with the experimental results. However, the DFT results sometimes give wrong predictions due to the lack of dispersive interactions. ${ }^{6}$ Thus, we need to discuss the stereoselectivity based on the MP2 energies.

Hereafter, all the discussion is based on the MP2 energies, otherwise specified. In the IMDA reactions of $\mathbf{1}$ and $\mathbf{2}$, for the
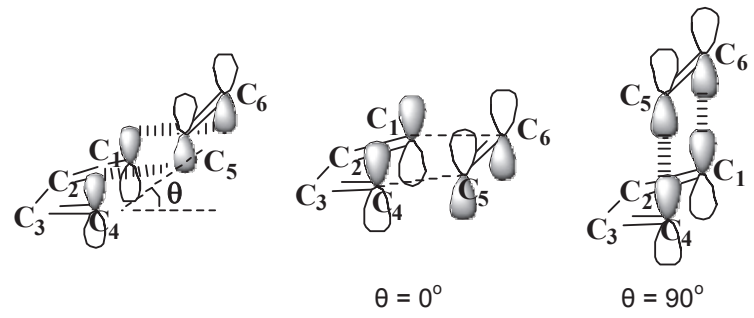

$\theta$ is the dihedral angle of $\mathrm{C}_{2} \mathrm{C}_{3} \mathrm{C}_{4} \mathrm{C}_{5}$ or $\mathrm{C}_{3} \mathrm{C}_{2} \mathrm{C}_{1} \mathrm{C}_{6}$.

\section{Scheme 1}

exo-cyclization, the boat-like TS is lower in energy than the chair-like TS, while for the endo-cyclization, the chair-like TS has lower energy than the boat-like TS. After all, the TSs for the exo-cyclization have lower energies than those for the endocyclization by 9.8 and $10.0 \mathrm{kcal} / \mathrm{mol}$ in the IMDA reactions of $\mathbf{1}$ and 2, respectively. This is consistent with the previous experimental observation ${ }^{5}$ that the treatment of $\mathbf{1}$ and $\mathbf{2}$ under thermal IMDA conditions resulted the undesired exo-cyclization contrary to the Tadano group's result. ${ }^{9}$

For $\mathbf{1}$ and 2, the origin of the energy difference between the TSs for the exo and the endo cyclization mainly originates from the steric effect and the orbital interactions. The steric repulsion between $-\mathrm{CH}_{2} \mathrm{OH}$ at $\mathrm{C} 11$ of the diene and $-\mathrm{CO}_{2} \mathrm{C}_{2} \mathrm{H}_{5}$ at $\mathrm{C} 2$ of the dienophile should be larger for the endo-cyclization than the exo-cyclization as can be noted in Figure 3. The TS structures for the exo and the endo-cyclization of $\mathbf{1}$ and $\mathbf{2}$ show the remarkable difference in the arrangement of the diene and the dienophile.

In addition, in the TS for the exo-cyclization, the dienophile (ene) was found to be located above the diene resulting in the strong orbital interactions, while for the endo-cyclization, the ene and the diene were almost in the same plane resulting in the weak orbital interactions as sketched in Scheme 1. This is clearly shown from the molecular orbital interactions based on 


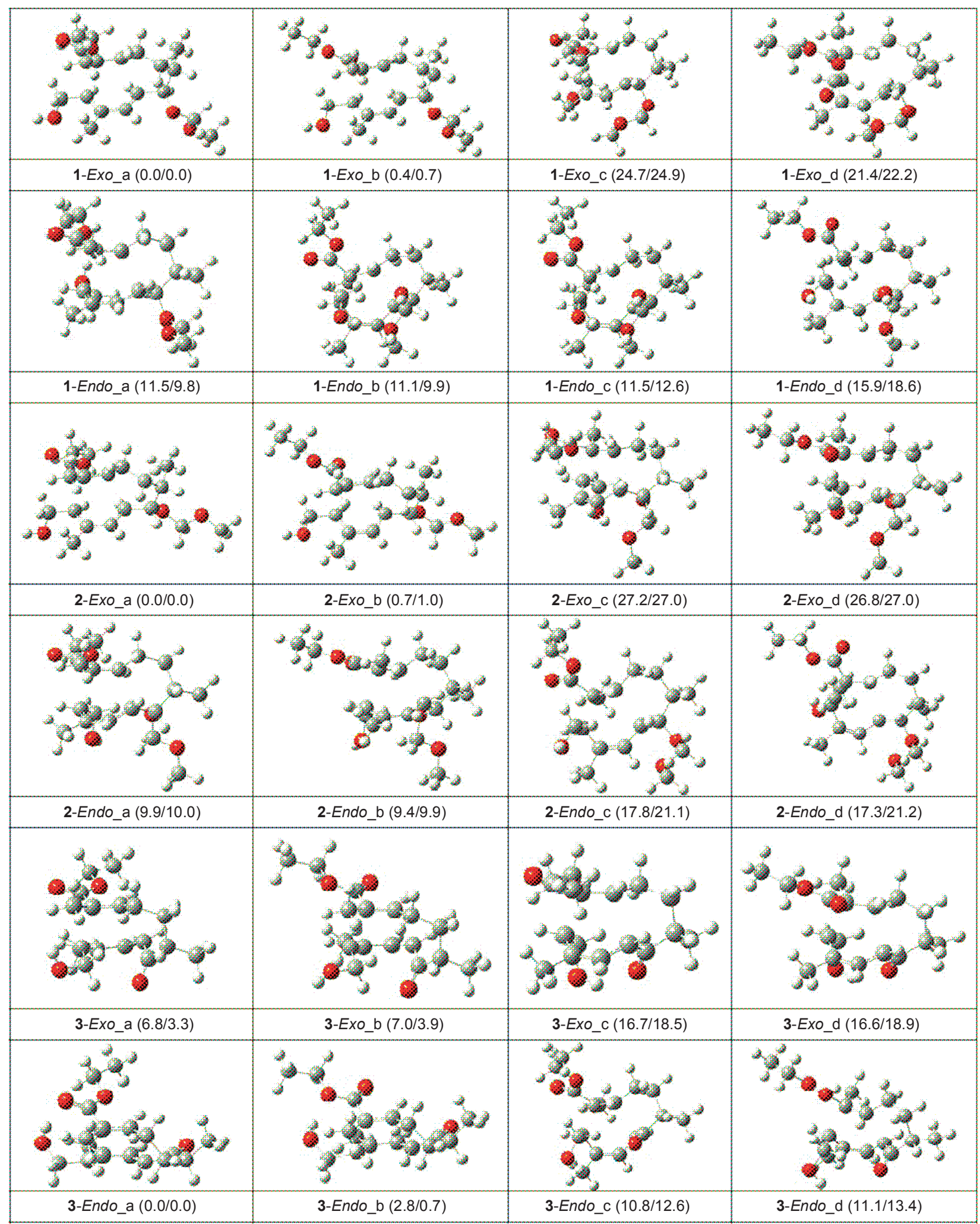

Figure 4. TS Structures for all exo and endo geometries. The relative energies represented in parentheses are in $\mathrm{kcal} / \mathrm{mol}(\mathrm{B} 3 \mathrm{LYP} / 6-31 \mathrm{G}(\mathrm{d}) /$ MP2 $/ 6-31+G(d))$.

the MO coefficients for the HOMO orbitals listed in Table 1. The orbital interactions $(\mathrm{A} \times \mathrm{B})$ (in arbitrary unit) in exo TSs are much larger than those in endo TSs for $\mathbf{1}$ and $\mathbf{2}$, while for 3, the orbital interactions in endo TS are larger than exo TS.
However, this approach can be applicable for one reactant with the same basis functions, and cannot be applicable for general purpose in different molecular systems or with different basis functions. Both the steric effect and the orbital interactions in 
Table 1. Orbital interactions between the $\pi$-orbitals of $\mathrm{C}_{1}$ and $\mathrm{C}_{6}$ and between those of $\mathrm{C}_{4}$ and $\mathrm{C}_{5}$.

\begin{tabular}{|c|c|c|c|c|c|c|}
\hline & \multicolumn{2}{|c|}{1} & \multicolumn{2}{|c|}{2} & \multicolumn{2}{|c|}{3} \\
\hline & Exo & Endo & Exo & Endo & Exo & Endo \\
\hline A & 0.0117 & 0.0003 & 0.0159 & 0.0003 & 0.0080 & 0.0230 \\
\hline B & 0.0176 & 0.0015 & 0.0270 & 0.0026 & 0.0379 & 0.0417 \\
\hline C & 0.0211 & 0.0015 & 0.0313 & 0.0027 & 0.0387 & 0.0476 \\
\hline
\end{tabular}

$\mathrm{A}$ and $\mathrm{B}$ are the absolute values of the product of the MO coefficients of the $\pi$-orbitals of $C_{1}$ and $C_{6}$ and $C_{4}$ and $C_{5}$ ) respectively. For example, $A=$ $\mathrm{C}_{\mathrm{Cl}, \mathrm{pz}} \times \mathrm{C}_{\mathrm{C} 6, \mathrm{pz}}$ where $\mathrm{C}_{\mu, \mathrm{pz}}$ is the $\mathrm{MO}$ coefficient of the $\mathrm{p}_{\mathrm{z}}$ orbital (z-axis is perpendicular to the bonding plane formed by $\mathrm{C} 1, \mathrm{C} 4, \mathrm{C} 5$, and $\mathrm{C} 6$ ) of the atom $\mu . \mathrm{C}=\left(\mathrm{A}^{2}+\mathrm{B}^{2}\right)^{1 / 2}$

the TSs favor the exo-cyclization over the endo-cyclization of $\mathbf{1}$ and $\mathbf{2}$, which is consistent with the experimental results. It should be noted that the difference in configuration $(R$ or $S$ ) at C7 does not change the preference of the exo cyclization of both 1 and 2 .

In the experiment, when the methoxymethoxy group at $\mathrm{C}_{7}$ was replaced by a carbonyl group to give 3 , the IMDA reaction resulted the endo-cyclized product. At first, it was quite surprise because the steric effect for $\mathbf{3}$ appears to be similar to those for $\mathbf{1}$ and $\mathbf{2}$. How the carbonyl group at $\mathrm{C}_{7}$ makes the difference? For $\mathbf{3}$, there exist additional $s$-cis and $s$-trans conformations in the arrangement of the diene and the carbonyl group along the $\mathrm{C}_{7}-\mathrm{C}_{8}$ bond. Previously, the exo/endo selectivity involving $s$-cis and $s$-trans conformations has been extensively explored. ${ }^{7}$ In our system of $\mathbf{3}$, the carbonyl group is involved in the diene. The calculated relative energies of the eight TSs for the 3-exo a, 3-exo b, 3-exo c, 3-exo d, 3-endo a, 3-endo b, 3-endo c, and 3-endo_d cyclizations are 3.3, 3.9, 18.5, 18.9, 0.0, 0.7, 12.6, and $13.4 \mathrm{kcal} / \mathrm{mol}$, respectively, which supports the endo preference in the IMDA reaction. It was found that the $s$-cis TSs are preferred to the corresponding s-trans TSs for both the exo and endo cyclization, where these two $s$-cis TSs are boat-like.

It has been pointed out that the concerted Diels-Alder reaction prefers the endo product while the stepwise reaction results in the exo structure. ${ }^{10}$ Generally, the extent of the synchronicity (concertedness) is measured by the difference between the distances of two bonds to be formed in the reactions. The calculated bond differences are 0.158 and $0.174 \AA$ for exo s-cis and endo $s$-cis transition states, respectively, and these are quite small. Therefore, it is reasonable that the energy of endo s-cis transition state is lower than the exo s-cis transition state. The contact distance of the $\mathrm{H}(\mathrm{C} 3)$ and $\mathrm{H}(\mathrm{C} 8)$ atoms in exo s-cis transition state is $2.280 \AA$. The electrostatic repulsion between these two $\mathrm{H}$ atoms also contributes to the higher energy for the exo cyclization than the endo cyclization. Oppositely, the steric effects between $-\mathrm{CH}_{2} \mathrm{OH}$ and $-\mathrm{CO}_{2} \mathrm{C}_{2} \mathrm{H}_{5}$ groups favors the exo cyclization than the endo one, which makes the energy difference between the exo and the endo cyclization smaller.

\section{Conclusion}

In summary, we investigated the stereoselectivity in the IMDA reactions of $\mathbf{1}, \mathbf{2}$, and $\mathbf{3}$ based on the MP $2 / 6-31+\mathrm{G}(\mathrm{d}) / /$ B3LYP/6-31G* calculations. All the possible TS structures were investigated and the relative energies are in excellent agreement with the experimental observations. The origin of the stereoselectivity mainly originates from the steric repulsion and the orbital interactions. It was also confirmed that the additional $s$-cis and $s$-trans conformations by introducing the carbonyl group at the neighbor of diene or dienophile may change the stereoselectivity, hence this kind of substitution can be utilized for stereoselective asymmetric synthesis.

Acknowledgments. This work was also supported by the Korea Science and Engineering Foundation (KOSEF) grant (No. 20100001630) funded by MEST. This research was also supported by a grant from the Fundamental R\&D Program for Core Technology of Materials funded by the Ministry of Knowledge and Economy, Republic of Korea.

\section{References}

1. (a) Houk, K. N.; González, J.; Li, Y. Acc. Chem. Res. 1995, 28, 81. (b) Kumar, A. Chem. Rev. 2001, 101, 1. (c) Corey, E. J. Angew. Chem. Int. Ed. 2002, 41, 1650. (d) Nicolaou, K. C.; Snyder, S. A.; Montagnon, T.; Vassilikogiannakis, G. Angew. Chem. Int. Ed. 2002, 41, 1668.

2. (a) Dewar, M. J. S.; Jie, C. X. Acc. Chem. Res. 1992, 25, 537. (b) Beno, B. R.; Houk, K. N.; Singleton, D. A. J. Am. Chem. Soc. 1996, 118, 9984. (c) Sodupe, M.; Rios, R.; Branchadell, V.; Nicholas, T.; Oliva, A.; Dannenberg, J. J. J. Am. Chem. Soc. 1997, 119, 4232. (d) Ge, M.; Stoltz, B. M.; Corey, E. J. Org. Lett. 2000, 2, 1927.

3. (a) Hosokawa, S.; Seki, M.; Fukuda, H.; Tatsuta, K. Tetrahedron Lett. 2006, 47, 2439. (b) Kim, J. Y.; Hwang, G.-S.; Lee, S. M.; Han, J. H.; Kim, E. Y.; Ryu, D. H. Bull. Korean Chem. Soc. 2009, 30, 289.

4. (a) Brieger, G.; Bennett, J. N. Chem. Rev. 1980, 80, 63. (b) Lilly, M. J.; Paddon-Row, M. N.; Sherburn, M.; Turner, C. I. Chem. Commun. 2000, 2213. (c) Tantillo, D. J.; Houk, K. N.; Jung, M. E. J. Org. Chem. 2001, 66, 1938. (d) Turner, C. I.; Williamson, R. M.; Paddon-Row, M. N.; Sherburn, M. S. J. Org. Chem. 2001, 66, 3963. (e) Cayzer, T. N.; Wong, L. S.-M.; Turner, P.; Paddon-Row, M. N.; Sherburn, M. S. Chem. Eur. J. 2002, 8, 739. (f) Takao, K.; Munakatam, R.; Tadano, K. Chem. Rev. 2005, 105, 4779. (g) Bradford, T. A.; Payne, A. D.; Willis, A. C.; Paddon-Row, M. N.; Sherburn, M. S. Org. Lett. 2007, 9, 4861.

5. (a) Lee, C.; Yang, W.; Parr, R. G. Phys. Rev. B 1988, 37, 785. (b) Becke, A. D. J. Chem. Phys. 1993, 98, 1372. (c) Becke, A. D. J. Chem. Phys. 1993, 98, 5648. (d) Gordillo, R.; Dudding, T.; Anderson, C. D.; Houk, K. N. Org. Lett. 2007, 9, 501.

6. (a) Houk, K. N.; Li, Y.; Evanseck, J. D. Angew. Chem. Int. Ed. 1992, 31, 682. (b) Jones, G. A.; Paddon-Row, M. N.; Sherburn, M. S.; Turner, C. I. Org. Lett. 2002, 4, 3789. (c) Bakalova, S. M.; Santos, A. G. J. Org. Chem. 2004, 69, 8475.

7. Frisch, M. J. et al. Gaussian 03; Gaussian, Inc.: Wallingford, CT, 2004.

8. (a) Coe, J. W.; Roush, W. R. J. Org. Chem. 1989, 54, 915. (b) Roush, W. R. In Comprehensive Organic Synthesis; Trost, B. M., Ed.; Pergamon: Oxford, 1991; Vol. 5, Chapter 4.4, pp 513-550. (c) Jung, M. E.; Huang, A.; Johnson, T. W. Org. Lett. 2000, 2, 1835.

9. Motozaki, T.; Sawamura, K.; Suzuki, A.; Yoshida, K.; Ueki, T.; Ohara, A.; Munakata, R.; Takao, K.; Tadano, K. Org. Lett. 2005, 7,2265

10. (a) Loncharich, R. J.; Brown, F. W.; Houk, K. N. J. Org. Chem. 1989, 54, 1129. (b) Birney, D. M.; Houk, K. N. J. Am. Chem. Soc. 1990, 112, 4127. (c) García, J. I.; Martinez-Merino, V.; Mayoral, J. A.; Salvatella, L. J. Am. Chem. Soc. 1998, 120, 2415. (d) PaddonRow, M. N.; Sherburn, M. S. Chem. Commun. 2000, 2215. (e) Kong, S.; Evanseck, J. D. J. Am. Chem. Soc. 2000, 122, 10418. (f) Bakalova, S. M.; Santos, A. G. J. Org. Chem. 2004, 69, 8475. (g) Pidaparthi, R. R.; Welker, M. E.; Day, C. S.; Wright, M. W. Org. Lett, 2007, 9, 1623. (h) Singh, R. S.; Adachi, S.; Tanaka, F.; Yamauchi, T.; Inui, C.; Harada, T. J. Org. Chem. 2008, 73, 212. 